\title{
Mass-independent fractionation of triple oxygen isotopes induced by hyperfine effect: The role of $\left(\mathrm{O}_{2}\right)_{2}$ dimerization
}

\author{
HAO YAN ${ }^{1,2}$, YONGBO PENG ${ }^{3}$, HUIMING BAO ${ }^{2,3}$ \\ ${ }^{1}$ SKLEG, Institute of Geochemistry, CAS, Guiyang 550081, \\ China (*correspondence: yanhao@mail.gyig.ac.cn) \\ ${ }^{2}$ Department of Geology \& Geophysics, Louisiana State \\ University, Baton Rouge, 70803, USA \\ ${ }^{3}$ International Center for Isotope Effects Research, Nanjing \\ University, Nanjing 210023, China
}

Thermal diffusion had been known to fractionate stable isotopes. However, Sun and Bao showed that massindependent ${ }^{17} \mathrm{O}$ anomalies can be generated simply by subjecting $\mathrm{O}_{2}$ gas in an enclosure to a thermal gradient ${ }^{[1,2]}$. By a method of exclusion, the authors proposed that a small defference in diffusion coefficient of gas molecules induced by nuclear spin is amplified during molecular collision. If the effect of nuclear spin (hyperfine effect) is indeed responsible for ${ }^{17} \mathrm{O}$ anomaly during thermal diffusion, it may play a role in gaseous nebulae discs and consequently in the puzzling triple oxygen isotope heterogeneity in solar system.

Since collision frequency is related to temperature, Sun and Bao's hypothesis would therefore predict that the $\theta$ $\left(=\ln \alpha^{17} \mathrm{O} / \ln \alpha^{18} \mathrm{O}\right)$ will change with temperture continuously. Here we conducted a series of close-system experiments on $\mathrm{O}_{2}$ diffusion along a thermal gradient with a temperature range from $78 \mathrm{~K}$ to $1023 \mathrm{~K}$. It is found that, within the temperature range from $168 \mathrm{~K}$ to $1023 \mathrm{~K}$, heavy isotopes are preferred in the cold end and the $\theta$ s remain constant to be at $\sim 0.48$. However, at temperature pair of $78 \mathrm{~K} / 168 \mathrm{~K}$ the fractionation exhibits an opposite trend in which heavy isotopes are enriched in the warmer end of $168 \mathrm{~K}$. In addition, the $\theta$ becomes 1.0 . We suggest that the formation of $\mathrm{O}_{2}-\mathrm{O}_{2}$ dimer at $78 \mathrm{~K}$ may be primarily responsible for the observed ${ }^{17} \mathrm{O}$ anomalies in Sun and Bao's and our experiments because spin-spin coupling accounts for $\sim 15 \%$ of van der Waals forces to bind two $\mathrm{O}_{2}$ molecules ${ }^{[3]}$. This hypothesis was further tested by applying an external magnetic field to hamper the dimerization of $\mathrm{O}_{2}$. We found that in this case at $78 \mathrm{~K}$ the ${ }^{17} \mathrm{O}$ anomalies are no longer observed. Thus, our results predict that thermal diffusion of $\mathrm{CO}$ would not generate a significant mass-independent ${ }^{17} \mathrm{O}$ anomaly.

[1] Sun and Bao, Rapid Commun. Mass Spectrom. 2011, 25, 20-24;

[2] Sun and Bao, Rapid Commun. Mass Spectrom. 2011, 25, 765-773;

[3] Aquilanti et al., Phys. Rev. Lett. 1999, 82, 69-72. 